\title{
A redescription of the adult male of Caecognathia cryptopais (Barnard, 1925) (Crustacea: Isopoda: Gnathiidae) from southern Africa
}

\author{
Nico J. Smit, Linda Basson and Jo G. Van As
}

Department of Zoology and Entomology, University of the Free State, PO Box 339, Bloemfontein, 9300, South Africa

Key words: Caecognathia cryptopais, redescription, taxonomy, morphology

\begin{abstract}
A redescription of the adult male of Caecognathia cryptopais (Barnard, 1925) is provided from syntypes and other material deposited in the South African Museum. The generic status of Caecognathia cryptopais is also revised. This redescription is based on light and scanning electron microscopy.
\end{abstract}

From their phylogenetic analysis of the family Gnathiidae, Cohen and Poore (1994), established 10 genera for the family. One of their significant taxonomic changes was the resurrection of the genus Caecognathia Dollfus, 1901. This genus is closely related to the genus Gnathia Leach, 1814. Cohen and Poore (1994) transferred many of the species described as belonging to the genus Gnathia to Caecognathia. Most of the species of Monod's (1926) Sectio Productae of the genus Gnathia were also moved to Caecognathia. The main taxonomic character distinguishing species of Caecognathia from those of Gnathia is the presence of a produced frontal border lacking any frontal processes.

All four gnathiid species from southern Africa have been described by Barnard (1914a,b, 1920, 1925a,b) as belonging to the genus Gnathia (Gnathia africana Barnard, 1914; Gnathia spongicola Barnard, 1920; Gnathia disjuncta Barnard, 1920 and Gnathia cryptopais Barnard, 1925). Due to the lack of sufficient information on their morphology, the southern African species were not included in Cohen and Poore's (1994) phylogenetic analysis and thus their generic status was not revised.

In the present study the type material in the South African Museum, Cape Town as well as other material in their collection was used to do a redescription of Caecognathia cryptopais and a revision of its generic status.

\section{MATERIALS AND METHODS}

For scanning electron microscopy specimens were rehydrated in a descending sequence of ethanol and washed in tap water in order to get rid of debris. They were then dehydrated to absolute ethanol and critical point dried. Specimens were mounted on aluminium stubs, sputter coated with gold and studied with the aid of a JEOL WINSEM JSM 6400 at $10 \mathrm{kV}$.
Temporary slides were prepared of whole mounts as well as dissected mouthparts and pereopods. These were examined with the aid of a Leitz Laborlux D compound as well as a Wild M5 dissection microscope and drawings made from projections using drawing attachments.

\section{RESULTS}

Caecognathia cryptopais (Barnard, 1925) Figs. 1-17

Syn.: Gnathia cryptopais Barnard, 1925

Description: Total length of syntype: $2 \mathrm{~mm}$ (SAMA6051). Total lengths of other material: 2-2.35 mm (mean $2.15 \mathrm{~mm}, \mathrm{n}=4$ ) (SAM-A43161), 2.05 and 2.15 $\mathrm{mm}(\mathrm{n}=2)($ SAM-A19310), $3.80 \mathrm{~mm}(\mathrm{n}=1)(\mathrm{SAM}-$ A19311), 3.65 and $3.75 \mathrm{~mm}(\mathrm{n}=2)(\mathrm{SAM}-\mathrm{A} 19312)$, 3.74 and $3.94 \mathrm{~mm}(\mathrm{n}=2)$ (SAM-A14602).

Cephalon. Rectangular, one and a half times as wide as long, posterior margin concave, lateral margins convex (Figs. 1, 12). Shallow dorsal sulcus, extending to median tubercle (Figs. 1, 11). Dorsal and ventral cephalon armed with numerous randomly distributed wart-like tubercles closely associated with long simple setae. Well developed oval-shaped, prominent bulbous, compound eyes on lateral margin of cephalon, slightly elevated and encircled by a smooth rim, length of eye slightly more than a fifth of cephalon (Figs. 3, 15). No paraocular ornamentation (Figs. 3, 11). Posterior median tubercle from middle of cephalon to posterior margin.

Frontal border. Rounded, produced for a fifth of cephalon's length, lacking any frontal processes (Figs. 2,13 ). Median groove on produced border, six to seven long simple setae on dorsal surface of median producing frontal border, rest of border covered with short simple setae. External scissura deeply excavated (Fig. 2). Supraocular lobe prominent, convex, extending laterally with five to seven tubercles. 

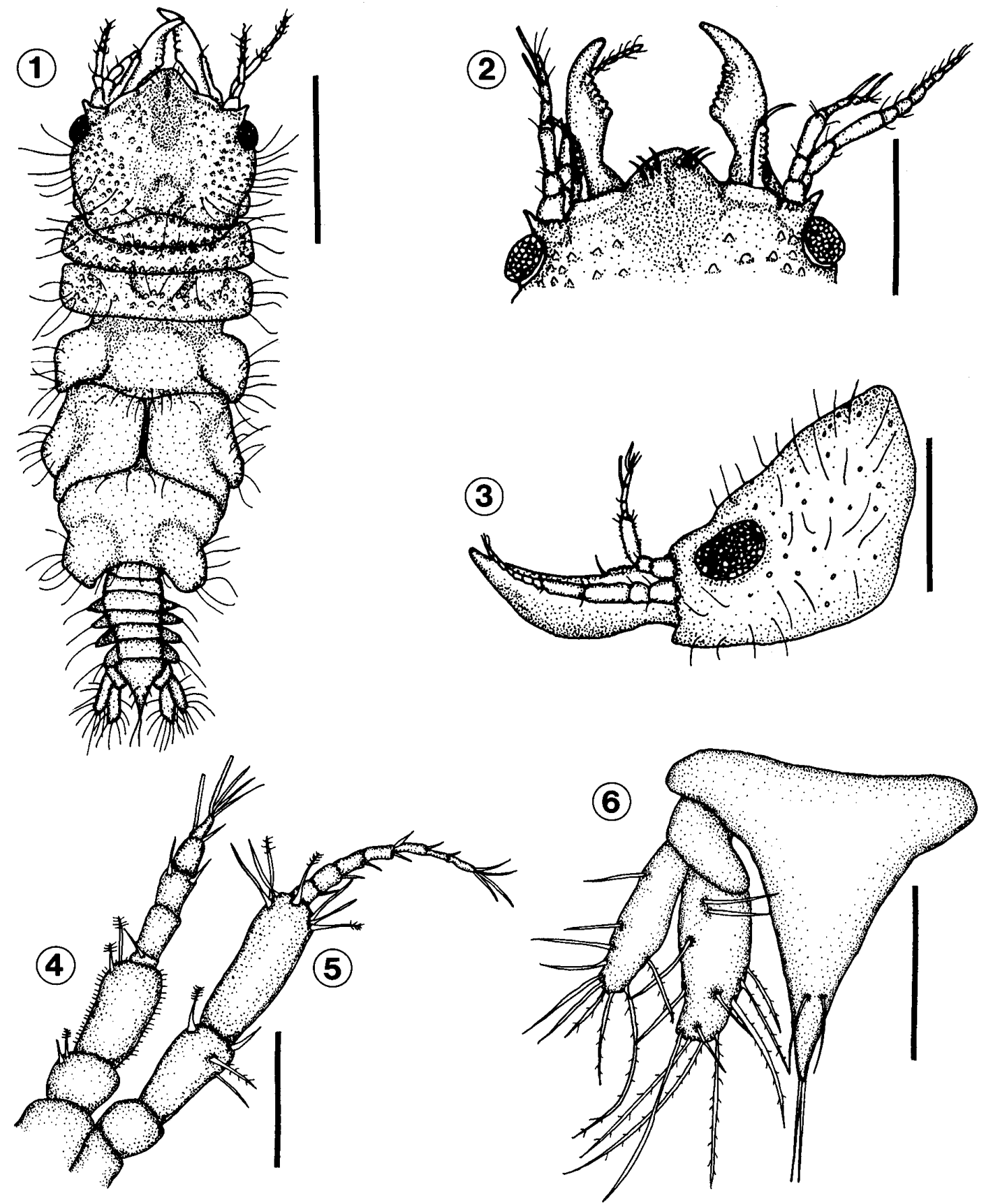

Figs. 1-6. Microscope projection drawings of a male Caecognathia cryptopais (Barnard, 1925) (SAM-A43161). Fig. 1. Full length dorsal view. Fig. 2. Frontal border and mandibles. Fig. 3. Lateral view of cephalon, antennae and mandible. Fig. 4. First antenna. Fig. 5. Second antenna. Fig. 6. Telson and uropods. Scale bars: Fig. $1=1 \mathrm{~mm}$; Figs $2,3=500 \mu \mathrm{m}$; Figs. $4-6=100 \mu \mathrm{m}$. 

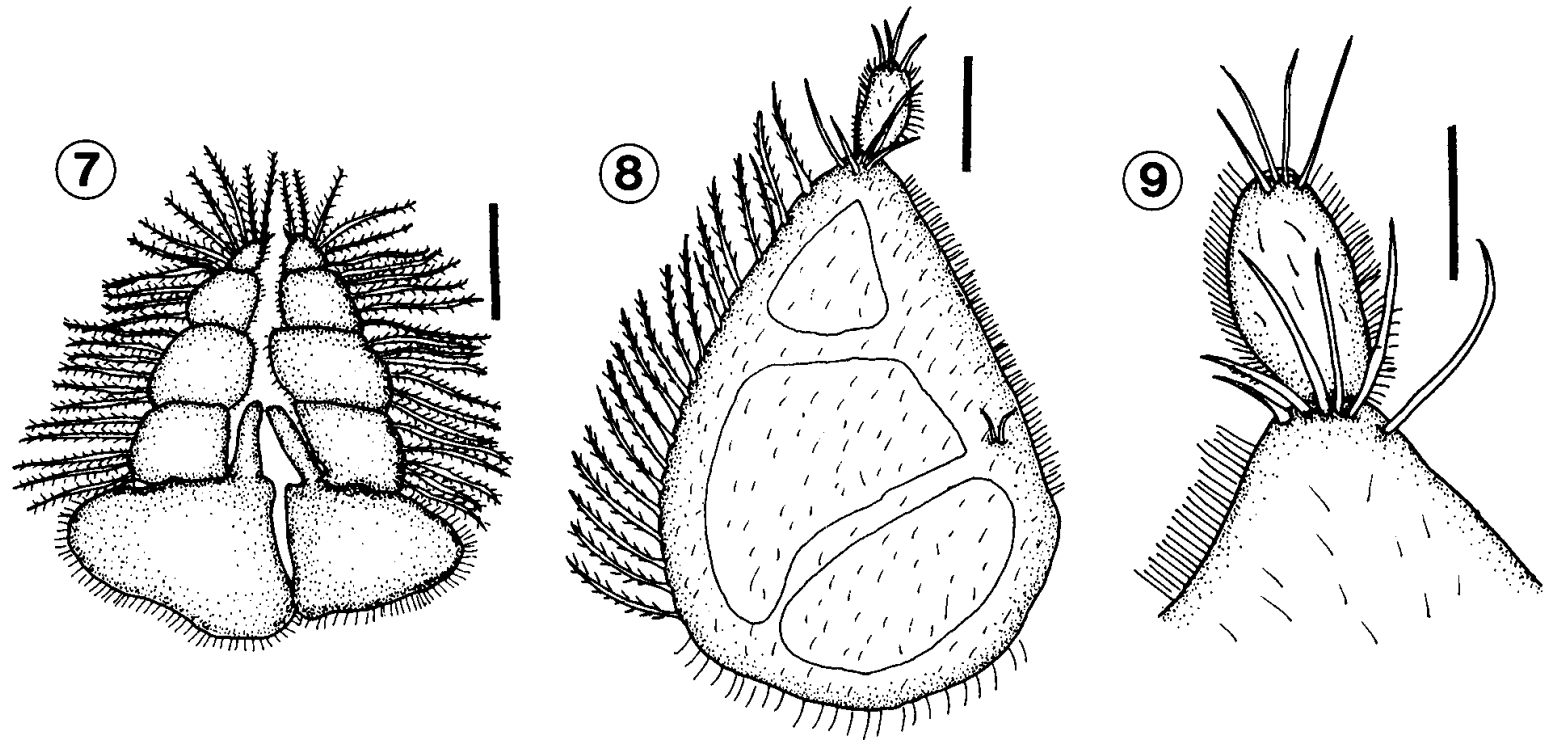

Figs. 7-9. Microscope projection drawings of the mouthparts of a male Caecognathia cryptopais (Barnard, 1925) (SAMA43161). Fig. 7. Maxillipede. Fig. 8. Pylopod. Fig. 9. Articles 2 and 3 of pylopod. Scale bars: Figs. 7, $8=100 \mu \mathrm{m}$; Fig. $9=50 \mu \mathrm{m}$.

Antennae. Antenna 2 longer than antenna 1. Antenna 1 with three peduncle articles, with third one largest and covered with short simple setae, flagellum with five articles, article 1 small, 2, 3 and 4 largest, article 4 with one aesthetascs setae, article 5 terminating in one aesthetascs and two to three simple setae, few setae on each article (Fig. 4). Antenna 2 with four peduncle articles, article 4 largest, flagellum with seven articles, article 1 largest (Fig. 5). Few long simple and feathered setae on each article.

Mandibles. Two thirds length of cephalon, twice as long as wide, outer border curved inwards, inner border straight with sparsely dentate blade (Figs. 2, 16). Apex cylindrical, curved inwards, distally raised in lateral view at $40^{\circ}$. Prominent incisor not present. Single mandibular setae extending from base of incisor process. Carina armed with 11 to 13 tubercles, forming ridge on lateral margin extending from basal neck to halfway along mandible (Figs. 2, 13). Internal lobe and pseudoblade absent. Short simple setae on ventral surface of blade.

Maxillipedes. Five-articled, proximal article largest, prominent endite of proximal article reaching article 3 , endite not contiguous with article 2 (Fig. 7). Lateral margins of distal four articles with plumose setae in order of 5-6-5-6 (Fig. 7). Mesial margins of distal four articles fringed with short simple setae. Palp three times as long as wide. No coupling hooks.

Pylopods. Three articles. First article greatly enlarged, pear-shaped, mesial and lateral borders convex, mesial border fringed with plumose setae, lateral and posterior fringing setae short and simple (Figs. 8, 14). Three distinct areolae. Ventral surface covered with short simple setae and six long simple setae distally. Second article oval, twice as long as wide, outer margin setose, ventrally also covered with short simple setae, three to five simple setae distally on ventral surface (Fig. 9). Third article minute.

Pereon. Twice as long as wide, wider than cephalon (Fig. 1). Pereonite 1 fused with cephalon, dorsally visible, not reaching lateral margins, anterior border convex, posterior border straight (Figs. 1, 12). Pereonites 2 and 3 of similar size, forming widest part of body. Pereonite 3 with anterior constriction but not separating it from pereonite 2. Prominent anterior constriction of pereonite 4 separating it from pereonite 3 . Pereonite 4 with distinct median groove extending to pereonite 6 , median groove forming oval tubercles on lateral margins of pereonites 4 to 6 (Fig. 1). Pereonite 5 and 6 not fused. Pereonite 6 narrowest, but longest, 1.6 times as long as wide, posterior margin deeply concave, without lobuii. Pereonite 7 dorsally visible, very small with rounded posterior margin, overlapping first pleonite. Dorsal and lateral pereon with wart-like tubercles closely associated with long simple setae.

Pleon. Pleon and pleotelson slightly less than a fifth of total length (Fig. 1). All five pleonites dorsally visible, epimera distinct. Single long medio-posterior simple seta on border of each pleonite, single long simple seta on epimera of all posterior four pleonites.

Pleotelson. Triangular, base not as wide as long, lateral margins slightly concave, ventral surface with many short simple setae and two to four long simple setae, distal apex terminating in pair of simple setae (Fig. 6). 

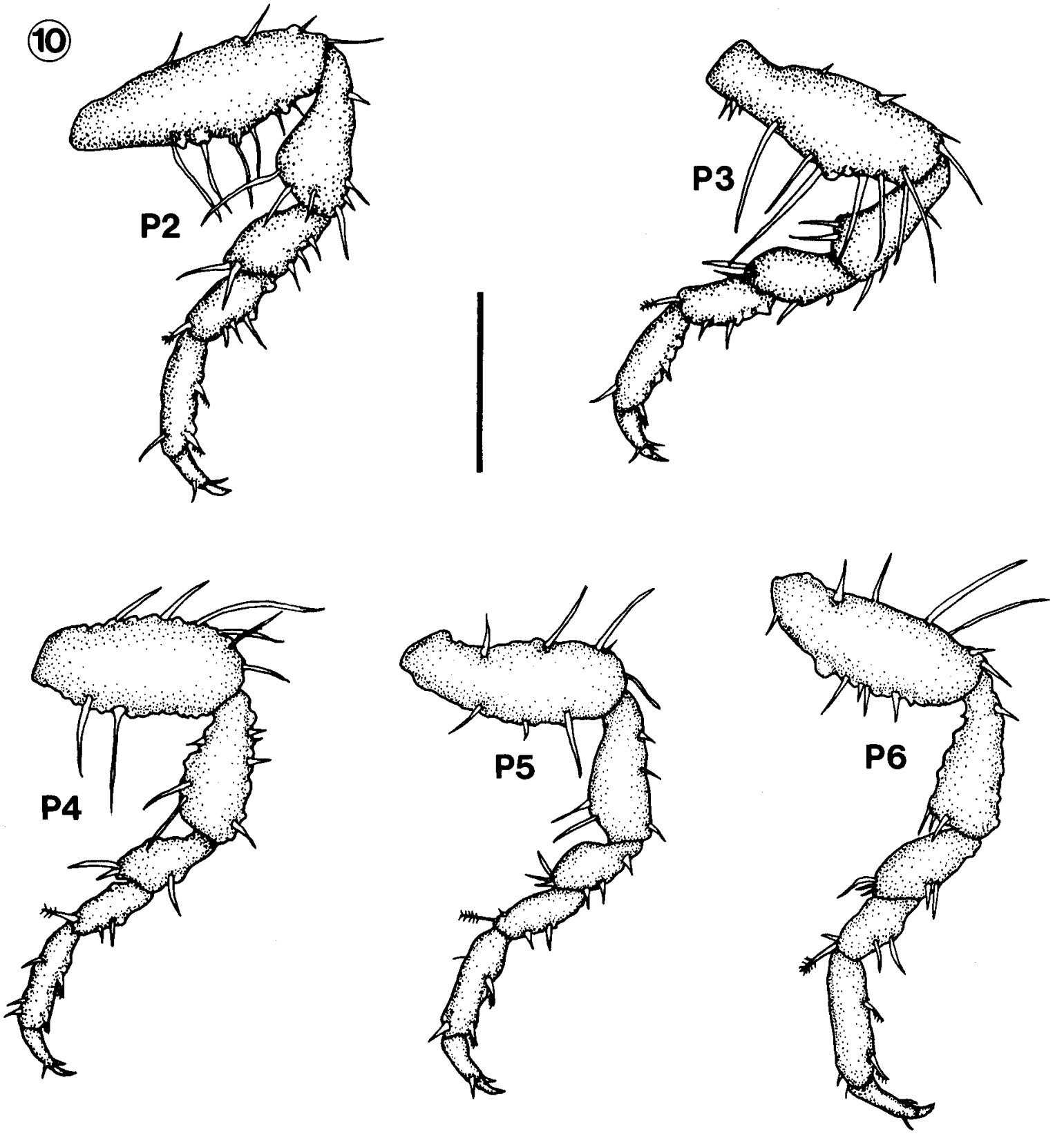

Fig. 10. Microscope projection drawings of pereopods 2 to 6 (P2-P6) of a male Caecognathia cryptopais (Barnard, 1925) (SAMA43161). Scale bar $=200 \mu \mathrm{m}$.

Uropods. Extending to apex of pleotelson, endopod longer and wider than exopod, both with long fringing setae, endopod with inner six plumose setae, four to six simple setae on dorsal surface, exopod with inner four plumose setae, rest of setae simple (Fig. 6).

Pereopods. Pereopod 2 consists of elongated basis with nine to eleven simple setae anterior and four to seven on posterior side, ischium two thirds length of basis, with three to five anterior setae and posterior tubercles with simple setae in between (Fig. 10). Merus is half the length of ischium with anterior bulbous protrusion, simple setae on bulbous protrusion, posterior margin with tubercles as well as simple setae. Carpus of almost same size and shape as merus, but without anterior bulbous protrusion single plumose seta on distal part of anterior margin. Basis, ischium, merus and carpus covered with short simple setae. Propodus about twice the length of carpus, prominent tubercles fringe posterior side, two elongated denticulated compound spines ending in sharp points situated on middle and distal part of posterior margin respectively, only a few simple setae anteriorly. Dactylus half the length of 

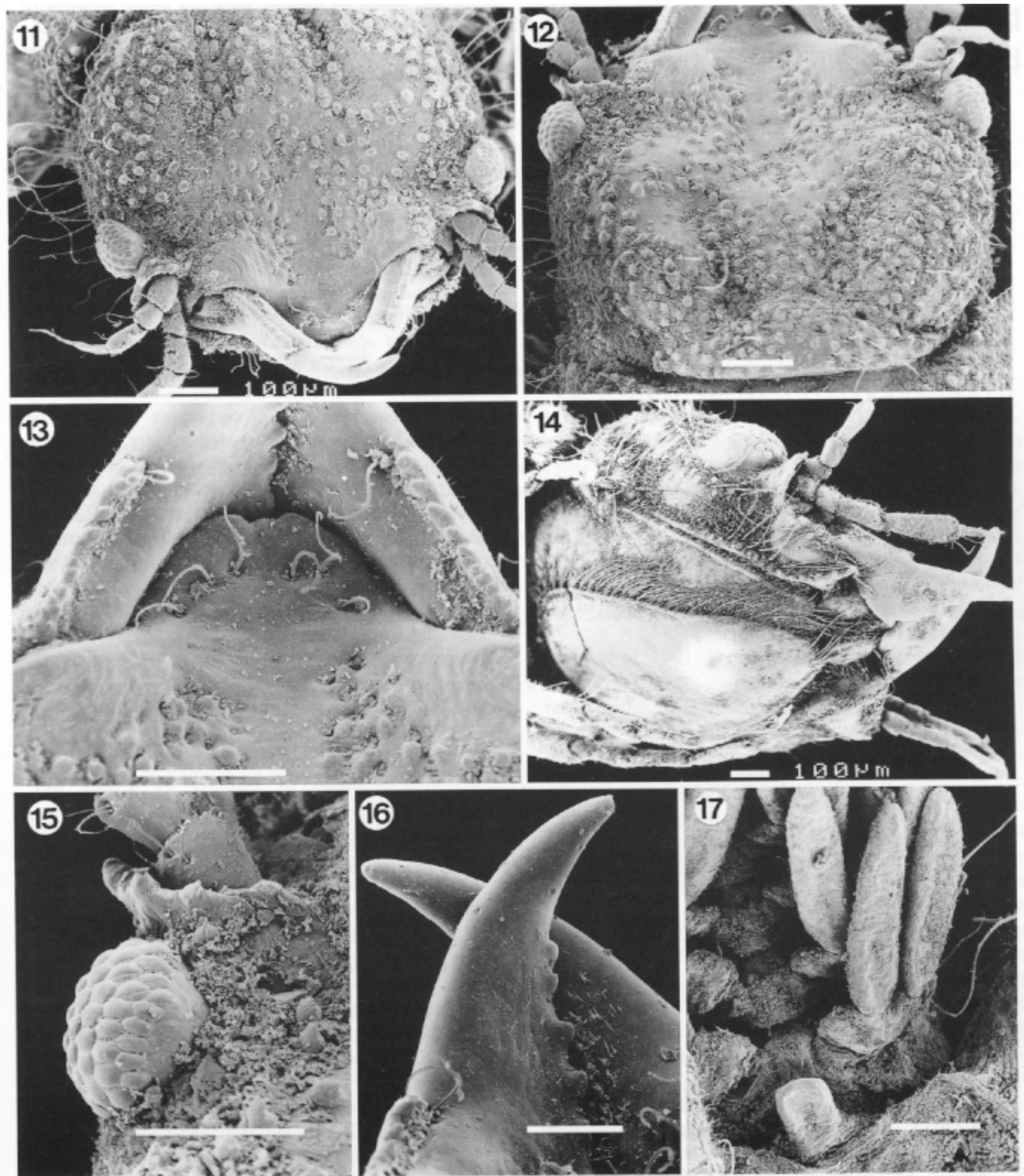

Figs. 11-17. Scanning electron micrographs of a male Caecognathia cryptopais (Barnard, 1925) (SAM-A43161). Fig. 11. Anterio-lateral view of cephalon. Fig. 12. Dorsal view of cephalon. Fig. 13. Dorsal view of produced frontal border with simple setae. Fig. 14. Ventral view of cephalon and pylopods. Fig. 15. Dorsal view of left eye and supraocular lobe. Fig. 16. Dorsal view of left mandible. Fig. 17. Ventral view of penes and first pleopods. Scale bars: Figs. 12, 13, 15, $17=100 \mu \mathrm{m}$; Fig. $16=$ $30 \mu \mathrm{m}$. 
propodus, terminates in sharp posterior pointing unguis, prominent spine on posterior side proximal to unguis with few simple setae on dorsal and ventral sides. Pereopods 3 to 6 similar to pereopod 2 (Fig. 10), differing only in direction, pereopods 4 to 6 are directed posteriorly and pereopods 2 and 3 anteriorly.

Pleopods. Five pairs of similar exo- and endopods, without fringing setae, short simple setae on distal borders (Fig. 17).

Penes. Large, one and a half times as long as wide, consist of two contiguous papillae (Fig. 17).

T y p e m a t e r i a 1: Syntypes: In the collection of the South African Museum, Cape Town (SAM-A6051). Original author designated no holotype.

T y p e 1 o c a 1 i t y : Duminy Point, off Saldanha Bay (E. $\times$ N. $0.5 \mathrm{~N}$., distant 8 nautical miles)

$\mathrm{O}$ t h e r 1 o c a 1 i t i e s : Off East London $\left(32^{\circ} 14.9^{\prime} \mathrm{S}\right.$, $\left.29^{\circ} 10.43^{\prime} \mathrm{E}\right), \quad\left(32^{\circ} 29.5^{\prime} \mathrm{S}, \quad 28^{\circ} 57.1^{\prime} \mathrm{E}\right)$ and $\left(32^{\circ} 28.6^{\prime} \mathrm{S}\right.$,

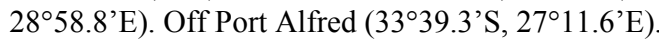

Type hos t: Unknown.

$\mathrm{M}$ a t e r i a 1 e x a m i n e d: Type material in the collection of the South African Museum, Cape Town (1 male, 1 larva, SAM-A6051).

O the r m a t e r i a $1:$ In the collection of the South African Museum, Cape Town (2 males, SAM-A14602) (2 males, SAM-A19310) (1 male, SAM-A19311), (2 males, SAMA19312), (4 males, SAM-A43161).

\section{DISCUSSION}

According to Cohen and Poore (1994) the genus Caecognathia is characterised by a produced frontal border without frontal processes, cephalon without paraocular ornamentation, pereonite immersed in cephalon, pylopod two- or three-articled, with article 1 enlarged and article 3 small or absent. Caecognathia cryptopais conforms to all these specifications for the genus and hence its transfer from the genus Gnathia to Caecognathia.

Caecognathia cryptopais differs from the other southern African species in that it is the only species with a rounded produced frontal border without any frontal processes, many wart-like tubercles on the body, no long simple setae on the distal margins of pleopods and very big penes in comparison with the other southern African species. According to Barnard (1925a,b, 1940), C. cryptopais is closely related to Caecognathia elongata (Kröyer, 1847) (syn. Gnathia cerina Stimpson, 1853) but differs in the presence of wart-like tubercles associated with long simple setae all over the dorsal and lateral surface of the body. Caecognathia elongata also has no prominent dorsal sulcus on pereonites 4 to 6 forming oval lobi laterales on pereonites 4 to 6. Monod (1926) as well as Barnard (1940) pointed out that C. cryptopais seems to be similar to Caecognathia antarctica (Studer, 1883). On examination of a single specimen of $C$. antarctica deposited in the South African Museum (SAM-A16158) it was found that it can be distinguished from $C$. cryptopais by its different shaped mandible, broader cephalon, a more prominent median tubercle and the indistinct epimera of the pleon. All the above mentioned species related to C. cryptopais were also transferred by Cohen and Poore (1994) from the genus Gnathia to Caecognathia.

Acknowledgements. The authors thank Ms. Michelle van der Merwe of the South African Museum, Cape Town, for making the gnathiid material available for examination and Dr. Gary Poore, Museum of Victoria, Australia, for confirming the new generic status of Caecognathia cryptopais. This study was funded by the marine resource program of the National Research Foundation (NRF) of South Africa.

\section{REFERENCES}

BARNARD K.H. 1914a: Contributions to the crustacean fauna of South Africa. 1. Additions to the marine Isopoda. Ann. S. Afr. Mus. 10: 197-230.

BARNARD K.H. 1914b: Contributions to the crustacean fauna of South Africa. 3. Additions to the marine Isopoda, with notes on some previously incompletely known species. Ann. S. Afr. Mus. 10: 325a-358a, 359-442.

BARNARD K.H. 1920: Contributions to the crustacean fauna of South Africa. 6. Further additions to the list of marine Isopoda. Ann. S. Afr. Mus. 17: 319-438.

BARNARD K.H. 1925a: Description of a new species of Gnathia (Crustacea, Isopoda) from South Africa. Ann. Mag. Nat. Hist. 15: 417-418.

BARNARD K.H. 1925b: Contributions to the crustacean fauna of South Africa. 9. Further additions to the list of Isopoda. Ann. S. Afr. Mus. 20: 381-412.

BARNARD K.H. 1940: Contributions to the crustacean fauna of South Africa. 12. Further additions to the Tanaidacea, Isopoda, and Amphipoda, together with keys for identification of the hitherto recorded marine and freshwater species. Ann. S. Afr. Mus. 32: 381-543.

COHEN B.F., POORE G.C.B. 1994: Phylogeny and biogeography of the Gnathiidae (Crustacea: Isopoda) with descriptions of new genera and species, most from southeastern Australia. Mem. Mus. Victoria 54: 271-397.

MONOD T. 1926: Les Gnathiidae. Essai monographique (Morphologie, Biologie, Systématique). Mem. Soc. Sci. Nat. Maroc 13: 1-668. 